Document downloaded from:

http://hdl.handle.net/10251/37258

This paper must be cited as:

Vivas Consuelo, DJJ.; Guadalajara Olmeda, MN.; Barrachina Martínez, I.; Poza Plaza, EDL. (2011). Explaining primary health care pharmacy expenditure using classification of medications for chronic conditions. Health Policy. 103(1):9-15. doi:10.1016/j.healthpol.2011.08.014.

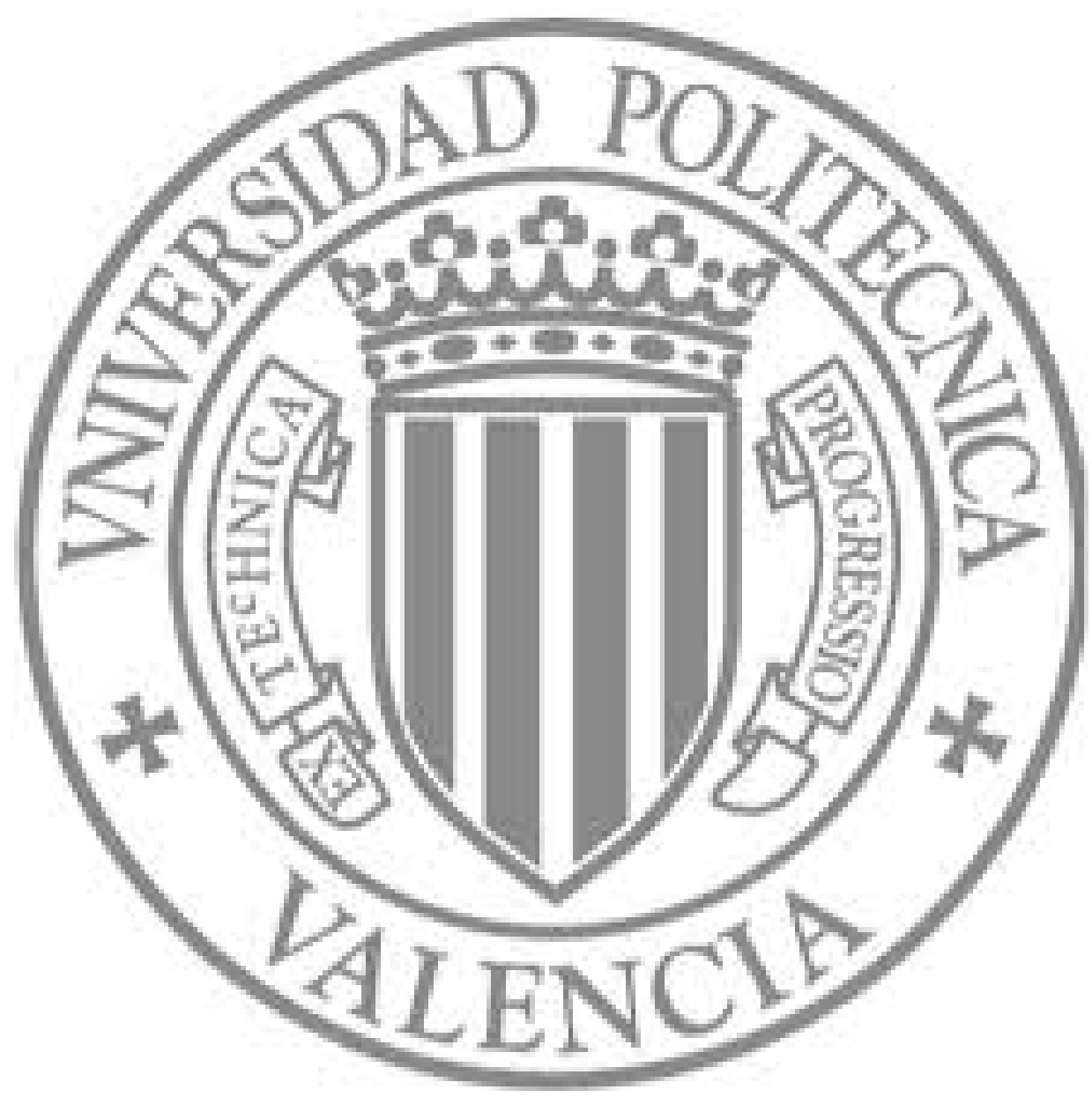

The final publication is available at

http://dx.doi.org/10.1016/j.healthpol.2011.08.014

Copyright Elsevier 


\title{
Explaining primary healthcare pharmacy expenditure using classification of medications for chronic conditions.
}

\author{
David Vivas*, Natividad Guadalajara*, Isabel Barrachina*, José-Luis Trillo**, Ruth Usó ${ }^{* *}$ and Elena \\ de-la-Poza*. \\ * Research Centre for Health Care Economic and Management. Universitat Politècnica de València. \\ Cno de Vera s/n. 46022 Valencia. Spain \\ ** Valencian Community Government. Health Department (Conselleria de Sanitat). General Direction of Pharmacy \\ and Pharmaceutical Products. Valencia. Spain
}

Corresponding author:

Prof. David Vivas

Research Centre for Health Care Economic and Management.

Universitat Politècnica de València.

Cno de Vera s/n.

46022 Valencia. Spain

Tel. +34963877062

Fax. +34963877962

dvivas@upv.es

\begin{abstract}
Background: The Valencian Autonomous Community (Spain) has implemented a scheme of purchasing services with the participation of public and private providers. Five districts are managed using PublicPrivate Partnership. The financing model is capitation and inter-centre invoice. The pharmaceutical benefits are not included in the per capita assignment.
\end{abstract}

Objectives: Modeling and explaining pharmacy expenditure using electronic prescriptions drug data.

Methods: A database of electronic prescription corresponding to 625,246 patients between Nov 2008 and Oct 2009 was used to run four linear models that explain the pharmaceutical expenditures. We take as dependent variable the neperian log of total pharmacy annual cost per patient in the primary health setting. The independent variables used combine demographics with revised classification in 18 chronic conditions obtained from the anatomical therapeutic chemical classification index (ATC).

Results: The retrospective model selected included: gender, pharmaceutical co-payment status and 8 dummy variables for the number of chronic conditions of each patient from 1 to 8 or more. The goodness-of-fit achieved is measured in $\mathrm{R}^{2}$ of $57 \%$.

Conclusions: These models must be considered in the current capitation system for pharmaceutical budgeting in a primary care setting established at regional level, as is the case in the Valencian Autonomous Community. The use of diagnostics and information regarding hospital encounters appears to be a complementary option for refining models of capitation of pharmaceutical and total health expenditure.

Author Keywords: Prescribed drugs, pharmaceutical expenditure, chronic condition, risk adjustment; capitation payments. 


\section{Introduction}

The National Health Systems which have introduced an internal market [1] to make resource allocation in health care more efficient [2] need risk adjustment models to achieve success. This is the case with the Spanish National Health System, which is completely decentralised to Autonomous Regions (Comunidades Autónomas).

The Valencian Regional Government, covering an area with a population of about 5,000,000, organizes health services through its Regional Health Authority (Conselleria de Sanidad), with a health care budget that is more than $40 \%$ of the total regional government's annual expenditure.

Since 2000 the Valencian Regional Health system has been involved in a process of creating an internal market between health districts to stimulate efficiency.

The Health System's functions of financing, purchasing and provision of services are separated from each other. The Regional Health Authority has the functions of stewardship [3], the Valencian Health Agency (Agencia Valenciana de Salud) is the purchaser and the 24 Health Districts (Departamentos de Salud) are the provider of services. Five of these districts are privately managed, using a formula of public-private partnership, denominated administrative concession. This model consists of an agreement between the public purchaser and a private company to construct a hospital and manage the health district for at least 10 years. After this period the hospital reverts to public ownership.

The financing model selected was capitation and inter-center invoicing - money following patient [4]. The health district receives an annual per capita quantity to attend to its assigned population: the flow of outgoing and incoming patients from other health districts generates an inter-center turnover to establish the corresponding balance ${ }^{1}$.

The pharmacy budget in primary health care is currently independent of this per capita assignment. The Valencian Health Agency is interested in a model of a risk adjustment system to control pharmacy spending.

At the same time, pharmaceutical spending is undergoing a very high growth, approximately $30 \%$ of overall health expenditure [5]. The Regional Health Authority has been studying a model of adjusting pharmaceutical expenditure based on chronic conditions and using electronic prescriptions drug data.

\section{Adjusting pharmaceutical expenditure background}

The starting point for our research is the Von Korff [6] approach. This group develops the Chronic Disease Score (CDS). They used population based automated outpatient pharmacy data in the United States (US) to construct a measurement of chronic disease status. The variables used were age, gender and health care visits. A replication of this study showed the validity of the model [7]. A refined CDS was developed including 28 conditions, age and sex, explaining $10 \%$ of the variation in total medical expenditure [8].

\footnotetext{
${ }^{1}$ In a Public-Private Partnership (PPP) health system, if a patient is treated anywhere other than his corresponding health district, the PPP health district has to pay the full Diagnosis-Related Group (DRG) cost. If patients from other health districts are treated in a hospital of a PPP health district, this pays $80 \%$ of the DRG cost. For others services not included in DRGs there are tariffs with the same criteria.
} 
Later, Malone [9] developed a chronic disease index using a medication database to approximate the number of chronic diseases a patient has. The index predicted the presence of three common diseases with a sensitivity of $\geq 75 \%$, and of six common diseases with a specificity of $\geq 75 \%$.

Lamers [10] replicated and extended the study on the revised CDS using automated outpatient pharmacy data from one Dutch sickness fund. They clustered 28 chronic conditions into seven Pharmacy Cost Groups (PCGs) in function of similarities in future costs, explaining $10 \%$ of differences in the following year's expenditures between patients. This gave an improvement of nearly twice the $R^{2}$ of $a$ model containing only demographic variables.

Other studies showed the predictive accuracy and validity of PCG for the Dutch health system [11], [12]. The correlation between medication and 28 chronic conditions was studied. This study showed that for 22 chronic conditions a majority of the prescriptions were for relevant diagnoses and therefore were considered indicative for specific chronic conditions [13].

Some models combining medicine code and diagnoses, Diagnostic Cost Groups, DCG/Rx [14] and Adjusted Clinical Groups ACG/Rx $[15,16]$, have proven their efficacy, but need diagnoses accuracy information that is not always available.

In Spain, a recent study shows that the adjusted capitation models based on pharmaceutical consumption are more explicative than those based only on diagnostics and are of a similar capacity to those combining both [17].

The objective of this paper is to analyze the influence of classification of medications for chronic conditions on the pharmaceutical expenditure in a primary health care setting, in order to develop a capitation adjusted model.

\section{Methods}

\section{Data}

A database of $12,893,852$ electronic prescriptions from health centres of Valencia Health Agency between Nov 2008 and Oct 2009 corresponding to a population of 625,246 was used, where 417,986 patients take some medicine. Each prescription contained patient identification, a code from the anatomical therapeutic chemical classification index (ATC-code) [18], cost and Defined Daily Doses (DDD) [19] and date. This information was linked with another database from the Population Information System with the following information for each person: age, gender, health district, health center and co-payment status. In Spain there is only co-payment for medicines. There are two categories of co-payment, co-payment level of $0 \%$ for pensioners and population without resources, and co-payment of $40 \%$ of price for the remaining.

To avoid including incidental users of medications under chronic conditions, persons were classified as chronic condition based on at least four prescriptions for the particular condition in the period of time studied.

The relation between medication and chronic conditions was studied using the revised CDS. This classification gives the ATC-code related with 25 chronic conditions. Table 1 shows information related to the 24 chronic conditions in primary care excluding HIV/AIDS. However, in this research only 18 diseases were included. Following Lamers [13], anxiety and tension, pain, and pain and inflammation were also excluded as the diagnoses on the prescriptions were not relevant for these conditions. Furthermore, a group of experts (physicians and pharmacists) from the Regional Health Authority assessed the relation between drugs and diagnoses and eliminated malignancies, HIV/AIDS, renal disease and transplantation from the study. These diseases were excluded due to the drugs used by these patients being dispensed in hospitals. 
Therefore a matrix was defined where the rows are the persons and the columns 18 chronic conditions, gender, age and co-payment status and pharmaceutical expenditure.

\section{Models}

To explore the association between annual costs per patient for each of the 18 chronic conditions, a factorial analysis was performed.

Later, we developed four models where the dependent variable was always total pharmacy cost per person and year in a primary care setting.

The models were estimated by means of ordinary least squares (OLS). Predictive performance of the model was evaluated by means of $R^{2}$-value, the $\mathrm{F}$ Snedecor and $T$ Student. The assumptions of normality, homoscedasticity and linearity were considered, and the logarithmic transformation was applied for the dependent variable ${ }^{2}$. Age was excluded due to the high correlation with the co-payment status (0.67). Once the models were obtained, the fulfillment of the three assumptions was proved through the analysis of the residuals.

The first model independent variables are: gender (dummy variable 0 female -1 male), co-payment status (dummy variable 1 without and 0 - 40\% co-payment). These variables were also included in all models with the exception of co-payment, which was excluded in the fourth model. In the second model three factors out of five were included and (OLS) regression analysis of factor was estimated.

The third model takes as independent variables one representative variable of each factor, selected by statistical and clinical criteria: hyperlipidemia (the highest correlated), depression (high correlated and high number of patients) and respiratory illness (high correlated and high number of patients) - all also as dummy variables.

Finally, we explored the relation between the dependent variable and the number of chronic diseases. Thus, we take in this case as independent variables: gender and 8 dummy variables for groups from only 1 chronic condition to 8 or more. The reason for which we have excluded the co-payment status from the model is because of its correlation with the number of chronic conditions.

\section{Results}

Pharmaceutical expenditure corresponding to chronic conditions amounts to $108,528,233$ Euros addressed to a total of 173,991 patients, which means that $27.82 \%$ of the population have some chronic condition, and supposes $58.2 \%$ of the total pharmaceutical expenditure. Table 1 shows the cost and number of patients for each disease.

The greatest cost is in drugs used to treat hyperlipidemia, at $17,075,134 €$, followed by respiratory illnesses, at $12,392,042 €$ and diabetes, at 10,381,386 €. These three pharmaceutical groups represent an expense of more than $36.7 \%$ of the total of drugs used for chronic conditions. The number of different chronic conditions suffered by each individual is determined by the number of different ATC groups. Figure 1 shows the number of chronic conditions related to age. The number of chronic diseases increases significantly from 50 years old until 75.

Five factors (Table 2) were obtained by factorial analysis. Factor one is the most relevant and represents the majority of cardiovascular diseases (coronary and peripheral vascular, cardiac disease) and their risk factors (hypertension, hyperlipidemia and diabetes), gout is associated with this factor, but with low coefficient and communality. The second factor included neuropsychiatric diseases (depression, epilepsy

\footnotetext{
${ }^{2}$ The proposed models are based on the normality of the variables. The compliance of the model will depend on the level of normality of its variables. As a result, the logarithm of the pharmaceutical expenditure is estimated as a better approach to its normal distribution.
} 
and psychotic illness). The third covers respiratory disease, rheumatism and peptic acid disease. Thyroids disease and tuberculosis are included in the fourth factor. TBC is negative correlated with this factor. The two variables composing this factor are inversely related. Parkinson's disease and Cystic fibrosis are included in the fifth. The five together explain $36.23 \%$ of the variance and the first three factors a $25.05 \%$. Two variables were not significant, glaucoma and Crohn's and ulcerative colitis.

Table 3 shows the results of the four models. Statistical significance checked by an F-test and T Student was over $99 \%$ for all of them.

The first model, sex and co-payment status has an $R^{2}$-value of $14.7 \%$. However, the more explicative variable is co-payment status. Women use more medicines than men.

The clinical and statistical explanation of the second model is weak. The first factor groups different chronic conditions with high prevalence - diabetes, hypertension and hyperlipidemia. To mix these diseases in a single factor is to limit the interpretation.

The third model, using the substitute variable of three factors (hyperlipidemia, depression and respiratory illness), reaches a $35.4 \%$ prediction, better than using the factors $(20.7 \%)$ (second model). If the 18 chronic conditions had been applied, model four, the goodness of fit would have reached $57.2 \%$.

Undoing the neperian logarithm transformation of expenditure, from the coefficients of the fourth model we can calculate the spending average for each group of patients. Thus, in Euros, a healthy woman without a chronic condition has an annual average spending on medicines of $8.01\left(\mathrm{e}^{2.081}\right)$ Euros and a man $5.47\left(\mathrm{e}^{2.081-0.381}\right)$ Euros. But in the case of patients with 8 or more chronic conditions the average expenditure was 3,763.11 $\left(\mathrm{e}^{2.081+6.152}\right)$ Euros for women and 2,570.87 $\left(\mathrm{e}^{2.081-0.381+6.152}\right)$ for men. The proportion increases when the number of chronic conditions of the patient increases. In last two columns of table 3 we give average amounts for each group in Euros.

\section{Discussion}

This contribution addresses the question of pharmaceutical cost containment and enhancing primary care. The models explaining the healthcare expenses based on demographic data have been improved by the introduction of chronic condition variables and diagnostics. Our research is focused only on primary heath drug expenditure and probably does not explain the total health cost in primary health care but resolves a problem of Health Authorities that need tools to manage and control the pharmaceutical spending.

The model would be improved if the cost of medications dispensed in hospitals were included. In such a case, diseases such as cancer, HIV/AIDS, renal disease and transplantation could be introduced into the model.

The fourth model seems the most convenient for Health Authorities to use in capitation allocation of budget to health districts and cost control, due to of its goodness of fit.

Recently some studies are using new systems of adjusting risk to explain health expenditures. Four are systems of diagnostic based risk adjusting: Diagnostic cost groups DCGs [20] , RxRisk model [21], Adjusted Clinical Groups (ACG) [22] and Clinical Risk Groups (CRG) [23-25].

Prinsze and Van Vliet [26], established that the combination of PCGs [13] and DCGs used in the Dutch social health insurance sector was complementary in the explanation of the health expenditure. This model's $R^{2}$ reached $22.8 \%$ in 2004.

Our model is retrospective, which is why it achieves a higher goodness-of-fit for explaining only pharmacy expenditure in primary health care with less number of variables, while other models explain the total health expenditure (primary health and hospital care) for a prospective application [27]. The results for total health spending must be considered in others studies. 
The variability in pharmacy costs was explained by ACG in Spanish health centers using patient electronic records [28]. This model is based on primary health care patient diagnostic; the explanation level is inferior to that obtained by us.

To examine how the model predicts prospective expenditure, further research is needed, using information from two consecutive years [15].

\section{Conclusions}

The models presented here improve the accuracy of risk-adjusted models for pharmaceutical expenditure in primary health care in National Health Systems such as the Spanish, where drug expenditure is the focus of discussion regarding efficiency, cost containment and system sustainability.

However, our models have been obtained for a population with determined features, which should be considered in any application of them where these features may vary.

The selected model is useful for adjusting the pharmaceutical spending in primary health care when there is no available information related to diagnosis, or such information is limited. Pharmaceutical information can, however, be obtained from the electronic prescribing system.

The use of diagnostics and information regarding hospital encounters appears to be a complementary option for refining models of capitation of pharmaceutical and total health expenditure.

\section{Acknowledgements}

The authors thank the General Direction of Pharmacy of the Valencian Department of Health for financial support and the working group for providing the data set. The opinions expressed in this paper are those of the authors and do not necessary reflect those of the afore-named. Any errors are the authors' responsibility. We would also like to thank the two anonymous reviewers for their comments, which helped greatly to improve this paper.

In memoriam of Philip Musgrove for his kindness and great contribution to economics of global health and development.

\section{References}

[1] Enthoven AC. Internal market reform of the British National Health Service. Health Aff (Millwood) 1991; 10:60-70.

[2] Musgrove P. Public spending on health care: how are different criteria related? Health Policy 1999; 47:207-23.

[3] Saltman RB, Ferroussier-Davis O. The concept of stewardship in health policy. Bull World Health Organ 2000; 78:732-9.

[4] Caballer-Tarazona M, Moya-Clemente I, Vivas-Consuelo D, Barrachina-Martínez I. A model to measure the efficiency of hospital performance. Mathematical and Computer Modelling 2010; 52:1095-102.

[5] Clemente J, Marcuello C, Montanes A. Pharmaceutical expenditure, total health-care expenditure and GDP. Health Econ 2008; 17:1187-206.

[6] Von Korff M, Wagner EH, Saunders K. A chronic disease score from automated pharmacy data. J Clin Epidemiol 1992; 45:197-203.

[7] Johnson RE, Hornbrook MC, Nichols GA. Replicating the chronic disease score (CDS) from automated pharmacy data. J Clin Epidemiol 1994; 47:1191-9.

[8] Clark DO, Von Korff M, Saunders K, Baluch WM, Simon GE. A chronic disease score with empirically derived weights. Med Care 1995; 33:783-95. 
[9] Malone DC, Billups SJ, Valuck RJ, Carter BL. Development of a chronic disease indicator score using a Veterans Affairs Medical Center medication database. IMPROVE Investigators. J Clin Epidemiol 1999; 52:551-7.

[10] Lamers LM. Pharmacy costs groups: a risk-adjuster for capitation payments based on the use of prescribed drugs. Med Care 1999; 37:824-30.

[11] Lamers LM. Health-based risk adjustment: is inpatient and outpatient diagnostic information sufficient? Inquiry 2001; 38:423-31.

[12] Lamers LM, Vliet RC. Health-based risk adjustment Improving the pharmacy-based cost group model to reduce gaming possibilities. Eur J Health Econ 2003; 4:107-14.

[13] Lamers LM, van Vliet RC. The Pharmacy-based Cost Group model: validating and adjusting the classification of medications for chronic conditions to the Dutch situation. Health Policy 2004; 68:113-21.

[14] Stam PJ, van Vliet RC, van de Ven WP. Diagnostic, pharmacy-based, and self-reported health measures in risk equalization models. Med Care 2010; 48:448-57.

[15] Hanley GE, Morgan S, Reid RJ. Explaining prescription drug use and expenditures using the adjusted clinical groups case-mix system in the population of British Columbia, Canada. Med Care 2010; 48:402-8.

[16] Kuo RN, Lai MS. Comparison of Rx-defined morbidity groups and diagnosis- based risk adjusters for predicting healthcare costs in Taiwan. BMC Health Serv Res 2010; 10:126.

[17] Calderon-Larranaga A, Abrams C, Poblador-Plou B, Weiner JP, Prados-Torres A. Applying diagnosis and pharmacy-based risk models to predict pharmacy use in Aragon, Spain: the impact of a local calibration. BMC Health Serv Res 2010; 10:22.

[18] WHO Collaborating Centre for Drug Statistics Methodology., Nordiska Läkemedelsnämnden. Guidelines for ATC classification. Oslo: WHO Collaborating Centre for Drug Statistics Methodology, 1993.

[19] WHO International Working Group for Drug Statistics Methodology. ATC/DDD classification (final). 2000.

[20] Pope GC, Ellis RP, Ash AS, Liu CF, Ayanian JZ, Bates DW, Burstin H, lezzoni LI, Ingber MJ. Principal inpatient diagnostic cost group model for Medicare risk adjustment. Health Care Financ Rev 2000; 21:93-118.

[21] Fishman PA, Goodman MJ, Hornbrook MC, Meenan RT, Bachman DJ, O'Keeffe Rosetti MC. Risk adjustment using automated ambulatory pharmacy data: the RxRisk model. Med Care, 2003:84-99.

[22] Sicras-Mainar A, Navarro-Artieda R. [Validating the Adjusted Clinical Groups [ACG] case-mix system in a Spanish population setting: a multicenter study]. Gac Sanit 2009; 23:22831.

[23] Hughes JS, Averill RF, Eisenhandler J, Goldfield NI, Muldoon J, Neff JM, Gay JC. Clinical Risk Groups (CRGs): a classification system for risk-adjusted capitation-based payment and health care management. Med Care 2004; 42:81-90.

[24] Garcia-Goni M, Ibern P, Inoriza JM. Hybrid risk adjustment for pharmaceutical benefits. Eur J Health Econ 2009; 10:299-308.

[25] Inoriza JM, Coderch J, Carreras M, Vall-Llosera L, Garcia-Goni M, Lisbona JM, Ibern P. [Measurement of morbidity attended in an integrated health care organization]. Gac Sanit 2009; 23:29-37.

[26] Prinsze FJ, van Vliet RC. Health-based risk adjustment: improving the pharmacy-based cost group model by adding diagnostic cost groups. Inquiry 2007; 44:469-80.

[27] Sales AE, Liu CF, Sloan KL, Malkin J, Fishman PA, Rosen AK, Loveland S, Paul Nichol W, Suzuki NT, Perrin E, Sharp ND, Todd-Stenberg J. Predicting costs of care using a pharmacybased measure risk adjustment in a veteran population. Med Care 2003; 41:753-60.

[28] Aguado A, Guino E, Mukherjee B, Sicras A, Serrat J, Acedo M, Ferro JJ, Moreno V. Variability in prescription drug expenditures explained by adjusted clinical groups (ACG) case- 
mix: a cross-sectional study of patient electronic records in primary care. BMC Health Serv Res 2008; 8:11. 
Table 1. Number of Patients, Prescriptions and Cost by Chronic Condition

\begin{tabular}{|c|c|c|c|c|c|}
\hline Chronic conditions / ATC-code & $\begin{array}{l}\text { Number of } \\
\text { Patients }\end{array}$ & $\begin{array}{l}\text { Number of } \\
\text { Prescriptions }\end{array}$ & Total cost $(€)$ & $\begin{array}{l}\text { Average cost } \\
\text { (€/patient) }\end{array}$ & $\begin{array}{l}\% \text { of patients } \\
\text { with chronic } \\
\text { condition } \\
\end{array}$ \\
\hline $\begin{array}{l}\text { Anxiety and tension } \\
\text { N05B }\end{array}$ & 38,558 & 500,909 & $1,371,736$ & 35.58 & $22.16 \%$ \\
\hline $\begin{array}{l}\text { Cardiac disease / ASCVD/CHF) } \\
\text { C01, C03C, C03EB01 }\end{array}$ & 25,910 & 343,366 & $2,704,798$ & 104.39 & $14.89 \%$ \\
\hline $\begin{array}{l}\text { Crohn's and ulcerative colitis } \\
\text { A07EC, (excluding A07EC01) }\end{array}$ & 809 & 9,054 & 364,253 & 450.25 & $0.46 \%$ \\
\hline $\begin{array}{l}\text { Coronary and peripheral vascular disease } \\
\text { C04AD03, B01A }\end{array}$ & 36,844 & 452,839 & $5,998,675$ & 162.81 & $21.18 \%$ \\
\hline $\begin{array}{l}\text { Cystic fibrosis } \\
\text { A09AA02 }\end{array}$ & 50 & 479 & 17,766 & 355.31 & $0.03 \%$ \\
\hline $\begin{array}{l}\text { Depression } \\
\text { N06AA, N06AB, N06AE, N06AF, N06AG, } \\
\text { N06AX }\end{array}$ & 29,937 & 339,120 & $8,410,054$ & 280.93 & $17.21 \%$ \\
\hline $\begin{array}{l}\text { Diabetes } \\
\text { A10A, A10B }\end{array}$ & 27,586 & 447,481 & $10,381,386$ & 376.33 & $15.85 \%$ \\
\hline $\begin{array}{l}\text { Epilepsy } \\
\text { N03A, (excluding N03AE01) }\end{array}$ & 10,313 & 119,088 & $5,119,687$ & 496.43 & $5.93 \%$ \\
\hline $\begin{array}{l}\text { Glaucoma } \\
\text { S01E }\end{array}$ & 12,853 & 201,165 & $3,170,014$ & 246.64 & $7.39 \%$ \\
\hline $\begin{array}{l}\text { Gout } \\
\text { M04A }\end{array}$ & 6,803 & 56,758 & 170,991 & 25.13 & $3.91 \%$ \\
\hline $\begin{array}{l}\text { Hyperlipidemia } \\
\text { C10A }\end{array}$ & 57,789 & 675,907 & $17,075,134$ & 295.47 & $33.21 \%$ \\
\hline $\begin{array}{l}\text { Hypertension } \\
\text { C02, C03A, C07, C08, C09A, C09B, C03EA01 }\end{array}$ & 58,091 & 788,670 & $8,412,175$ & 144.81 & $33.39 \%$ \\
\hline $\begin{array}{l}\text { Malignancies } \\
\text { L01, (excluding L01BA01) , L03AA02, } \\
\text { L03AA03, L03AA10, A04AA }\end{array}$ & 595 & 8,108 & $3,682,997$ & $6,189.91$ & $0.34 \%$ \\
\hline $\begin{array}{l}\text { Pain } \\
\text { N02A } \\
\end{array}$ & 10,356 & 179,358 & $3,445,931$ & 332.75 & $5.95 \%$ \\
\hline $\begin{array}{l}\text { Pain and inflammation } \\
\text { M01A }\end{array}$ & 45,202 & 446,745 & $5,066,451$ & 112.08 & $25.98 \%$ \\
\hline $\begin{array}{l}\text { Parkinson's disease } \\
\text { N04B }\end{array}$ & 1,808 & 27,797 & $1,695,455$ & 937.75 & $1.04 \%$ \\
\hline $\begin{array}{l}\text { Peptic acid disease } \\
\mathrm{A} 02 \mathrm{~A}, \mathrm{~A} 02 \mathrm{~B}\end{array}$ & 63,640 & 731,357 & $7,877,462$ & 123.78 & $36.58 \%$ \\
\hline $\begin{array}{l}\text { Psychotic illness (including bipolar disorders) } \\
\text { N05A }\end{array}$ & 8,485 & 135,328 & $8,672,691$ & $1,022.12$ & $4.88 \%$ \\
\hline $\begin{array}{l}\text { Renal disease (including ESRD) } \\
\text { B03XA01, V03AE01 }\end{array}$ & 128 & 957 & 30,511 & 238.37 & $0.07 \%$ \\
\hline $\begin{array}{l}\text { Respiratory illness, asthma } \\
\text { R03 }\end{array}$ & 18,913 & 312,239 & $12,392,042$ & 655.21 & $10.87 \%$ \\
\hline $\begin{array}{l}\text { Rheumatologic conditions } \\
\text { H02, M01CB, M01CC01, P01BA02, L01BA01, } \\
\text { A07EC01 }\end{array}$ & 4,911 & 71,601 & 875,878 & 178.35 & $2.82 \%$ \\
\hline $\begin{array}{l}\text { Thyroid disorders } \\
\text { H03A, H03B }\end{array}$ & 8,716 & 50,843 & 157,945 & 18.12 & $5.01 \%$ \\
\hline $\begin{array}{l}\text { Transplantations } \\
\text { L04AA01, L04AA05, L04AA06, L04AX01 }\end{array}$ & 828 & 18,724 & $1,415,102$ & $1,709.06$ & $0.48 \%$ \\
\hline $\begin{array}{l}\text { Tuberculosis } \\
\text { J04A }\end{array}$ & 231 & 1,769 & 19,100 & 82.68 & $0.13 \%$ \\
\hline Total patients with chronic condition & 173,991 & $5,919,662$ & $108,528,233$ & 623.76 & $27.82 \%$ \\
\hline Total population & 625,246 & & $186,552,001$ & 298.37 & \\
\hline
\end{tabular}


Table 2. Results of Factorial Analysis of Variables

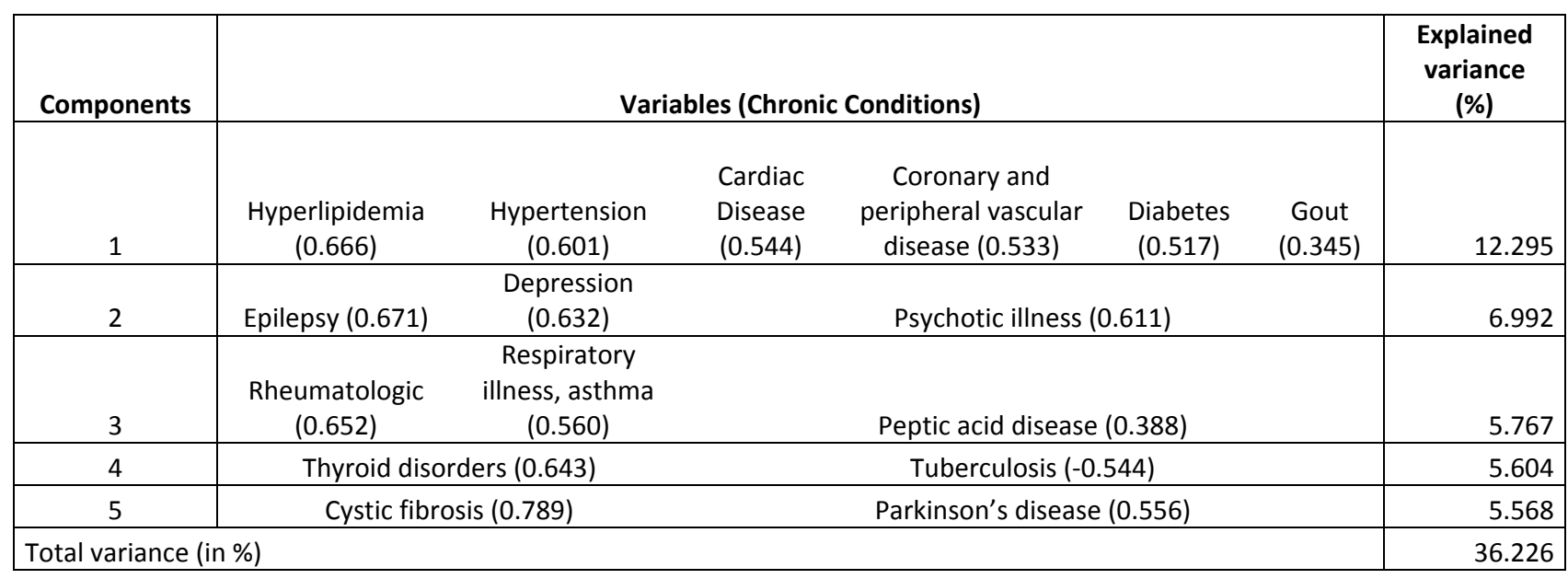

\begin{tabular}{|l|l|r|}
\hline Kayser- Meyer-Olkin index & \multicolumn{2}{|c|}{0.755} \\
\hline & Chi-square approximation & $401,309.44$ \\
Bartlett's test & Gl & 153 \\
\hline
\end{tabular}

Rotation has converged in 6 interactions. Method: Principal component analysis. Analytic rotation in factor analysis: Varimax with Kaiser. In brackets after the conditions the correlation coefficient between its corresponding factor and this variable is shown. 
Table 3. Results of Models

\begin{tabular}{|c|c|c|c|c|c|c|}
\hline \multirow[b]{2}{*}{ Variables } & \multirow{2}{*}{$\frac{\text { Model 1 }}{\beta}$} & \multirow{2}{*}{$\frac{\text { Model } 2}{\beta}$} & \multirow{2}{*}{$\begin{array}{c}\text { Model } 3 \\
\beta\end{array}$} & \multirow{2}{*}{$\begin{array}{c}\text { Model } 4 \\
\beta \\
\end{array}$} & \multicolumn{2}{|c|}{\begin{tabular}{|c|}
$\begin{array}{c}\text { Cost by patient } \\
\text { according to model } \\
4 \text { (in Euros)* }\end{array}$ \\
\end{tabular}} \\
\hline & & & & & Women & Men \\
\hline (Constant) & 2.657 & 2.849 & 2.394 & 2.081 & & \\
\hline Gender & -0.489 & -0.550 & -0.412 & -0.381 & & \\
\hline Co-payment status & 2.126 & 1.552 & 1.154 & & & \\
\hline Factor 1 & & 0.689 & & & & \\
\hline Factor 2 & & 0.415 & & & & \\
\hline Factor 3 & & 0.267 & & & & \\
\hline Hyperlipidemmia & & & 3.069 & & & \\
\hline Depression & & & 2.601 & & & \\
\hline Respiratory illness & & & 2.953 & & & \\
\hline 1 chronic condition & & & & 3.746 & 339.34 & 231.83 \\
\hline 2 chronic condition & & & & 4.480 & 706.98 & 482.99 \\
\hline 3 chronic condition & & & & 4.907 & $1,083.55$ & 740.26 \\
\hline 4 chronic condition & & & & 5.213 & $1,471.44$ & $1,005.26$ \\
\hline 5 chronic condition & & & & 5.465 & $1,893.15$ & $1,293.36$ \\
\hline 6 chronic condition & & & & 5.697 & $2,387.50$ & $1,631.08$ \\
\hline 7 chronic condition & & & & 5.928 & $3,007.91$ & $2,054.94$ \\
\hline 8 o more & & & & 6.152 & $3,763.11$ & $2,570.87$ \\
\hline$N(625,246)$ & & & & & & \\
\hline Mean squared error & 5.863 & 5.450 & 4.436 & 2.940 & & \\
\hline$R^{2}$ & 0.147 & 0.207 & 0.354 & 0.572 & & \\
\hline $\mathrm{F}$ & $53,680.449$ & $32,573.217$ & $68,608.995$ & $92,878.019$ & & \\
\hline
\end{tabular}

Dependent variable was the neperian logarithm of annual cost in Euros per patient.

*The algorithm for women is $\mathrm{e}^{2.081-0.381+\beta \text {, }}$ and men $\mathrm{e}^{2.081+\beta}$ 
Figure 1. Patient distribution by number of chronic diseases and age.

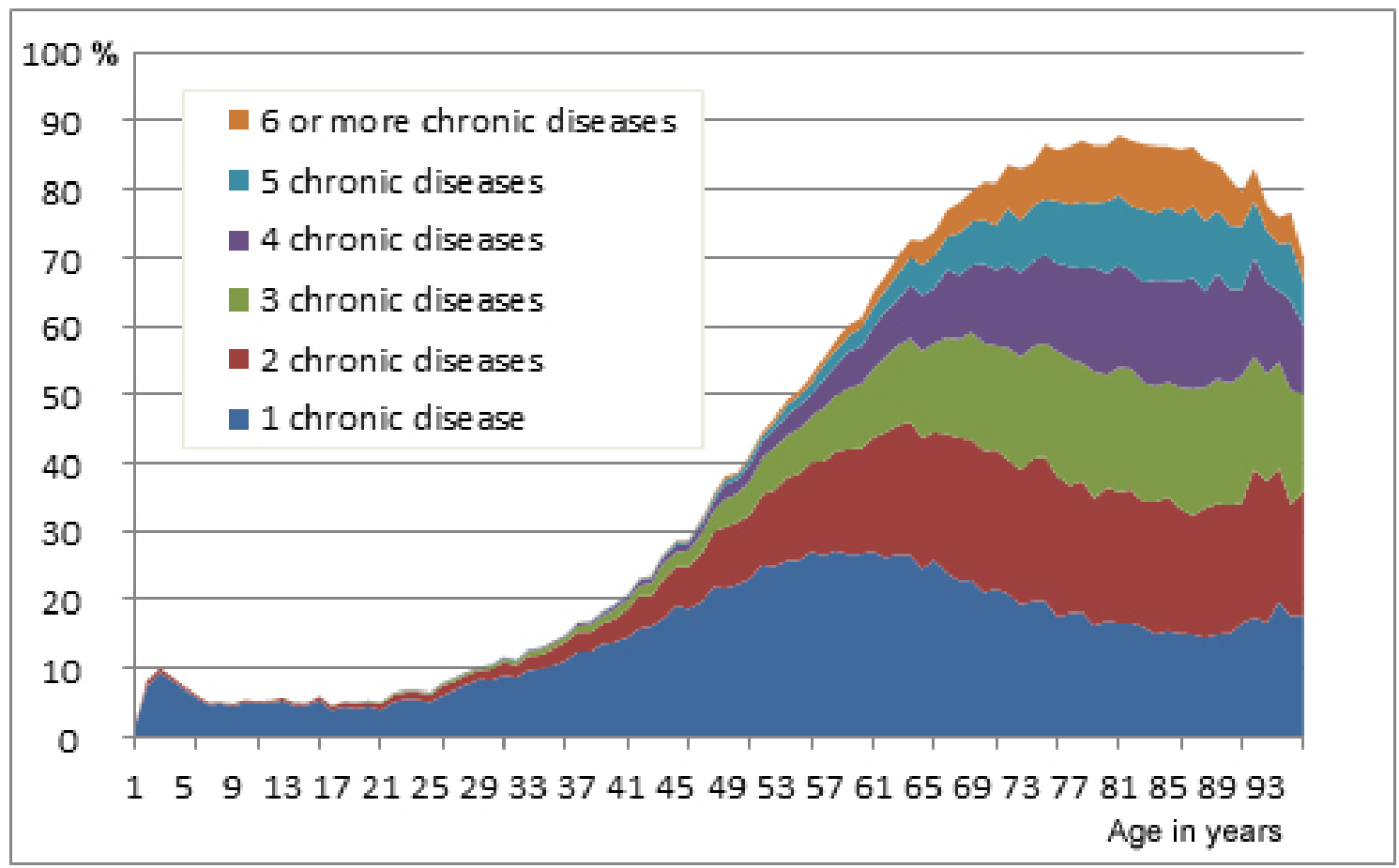

